\title{
Anti-migratory and cytotoxic properties of medicinal plants against melanoma (Poster number
}

\author{
A. Alqathama ${ }^{1}$, J.M. Prieto ${ }^{2}$. \\ ${ }^{1}$ School of Pharmacy, Um-al-Qura University, Makkah, Kingdom Saudi Arabia. \\ ${ }^{2}$ UCL School of Pharmacy, Department of Pharmaceutical \& Biological Chemistry, London, \\ United Kingdom.
}

Background: Malignant melanoma is the most aggressive form of skin cancer. As natural products are an important source of new anti-cancer lead compounds, the aim of this study is to screen selected Saudi medicinal plants for anti-melanoma activity by evaluating their effects on cell proliferation, viability, cell cycle profile, apoptosis induction and migration, as well as to characterize the active principle compounds.

Material and Method: Several fractions (hexane, chloroform and water) of the methanol extracts of selected Saudi medicinal plants were tested against melanoma cell lines. The cytotoxic effects of the extracts were determined by Sulforhodamine B staining and Alamar Blue assay. Further mechanistic studies were performed namely caspase 3/7 activity assay and cell cycle analysis. A 2D migration assay was conducted and phytochemical analyses were performed using HPLC and SPE techniques.

Results and Discussion: The extracts showing significant cytotoxic effects (IC50 shown in $\mathrm{mg} / \mathrm{ml}$ ) are the chloroform fraction of Haplophyllum tuberculatum (HT) (6.058), Capparis decidua (CD) (15.95), Aizoon canariense (AC) (20.58), Carissa edulis (CE) (47), Cyperus rotundus (CR) (70.32), Otostegia fruticosa (OF) (88.45), Osteospermum vaillantii (OV) (44.04), Pulicaria inuloides (39.84), Grewia tenax (GT) (83.29), the hexane fraction of Euryops arabicus (EA) (87.89), Plicosepalus curviflorus (PC) (30.86) and the aqueous fraction of Acacia nilotica (AN) (20.29). Cell cycle analysis showed that GT, HT and PC were able to arrest cell cycle at $S$ phase whereas $C D$ induced $G 2 / M$ arrest. The activity of caspase 3/7 was induced by CE, EA, GT, HT and PC. The hexane fraction of OV was the only extract inhibiting melanoma cell migration.

Conclusion: The cytotoxic effects of CE, GT, HT and PC are characterized by cell cycle arrest at $S$ phase, in association with the induction of apoptosis whereas $C D$ induced cell cycle arrest at G2/M. OV extract possesses anti-migratory effect in melanoma. Isolation of the active principles and identification of the mechanisms of action are in progress.

Published in

European Journal of Cancer, Volume 50, Supplement 5, July 2014, Page S198. 